\title{
Endüstri 4.0'ın İş Süreçleri Yönetimine Etkisi: Akıllı Depolama Sistemi Uygulaması
}

\author{
Impact of Industry 4.0 on Business Process Management: Smart Storage System Application
}

\section{Emre BILGIN SARI}

Dr. Arş. Gör., Dokuz Eylül Üniversitesi, İ̈BF,

Işletme Bölümü, Üretim Yönetimi ve Pazarlama A.B.D.,

emre.bilgin@deu.edu.tr

https://orcid.org/0000-0001-5110-1918

\section{Onur ÖZVERí}

Prof. Dr., Dokuz Eylül Üniversitesi, IİBF,

İsletme Bölümü, Saylsal Yöntemler A.B.D.,

onur.ozveri@deu.edu.tr

https://orcid.org/0000-0001-9203-9179

\section{Umut Ekrem SSENYAY}

Yüksek Lisans Öğrencisi, Dokuz Eylül Üniversitesi,

SBE, İsletme Yönetimi A.B.D.,

ekremsenyay@gmail.com

https://orcid.org/0000-0002-8722-1046
Makale Başvuru Tarihi: 25.07.2019

Makale Kabul Tarihi: 25.09.2019

Makale Türü: Araştırma Makalesi

\section{Anahtar \\ Kelimeler:}

İ̧S Süreç Yönetimi,

Nesnelerin

Interneti.

Akıllı Sistemler,

Akıllı Depolama,

Endüstri 4.0,

Keywords:

$B P M$,

IoT,

Smart Systems,

Automated Storage and Retrieval System,

\section{ÖZET}

Endüstri 4.0 hayatın her alanında yarattı̆g etki ile bir devrim olarak kabul edilmektedir. Bu devrim işletmeler üzerinde pek çok konuda ve süreçte kendisine uygulama alanı bulmaktadır. İş süreçleri yönetimi (BPM) de işletmeler içinde yapllan işlerin bir sistematik dahilinde sürdürülmesini amaçlayan yaygın bir ilkedir. Endüstri 4.0 diğer pek çok alanda olduğu gibi BPM üzerinde de bazı etkileri bulunmaktadır. Bu çalışmada Endüstri 4.0'ın BPM üzerindeki etkilerinin ortaya çıkarılması amacıyla geleneksel bir depolama sürecinin yerine akıllı depolama sistemi kurulması ile dijital bir çalışma alanı yaratılması konusu ele alınmaktadır. Çalışmanın uygulama çıktıları bölümünde akıllı depolama sisteminin sağladı̆̆ katkılar paylaşılmaktadır. Çalışmanın sonucu olarak akıllı depolama sisteminin işletmeye sağladığ yönetsel katkılar ve maliyet etkinliği sunulmaktadir.

Industry 4.0, 


\section{Gİiș}

Günümüzde işletmeler inovasyon odaklı, maliyetleri düşüren, müşteri ihtiyaçlarına daha iyi yanıt vererek optimum çözümler sunan ak1llı sistemler ile yeni bir paradigmaya geçmektedir. Endüstri 4.0 olarak isimlendirilen ve bir devrim niteliğinde olan bu dönüşüm kaynağ 1 , iş modelleri üzerinde yarattığı etki ile pek çok yönetim kavramının yeniden ele alınmasına neden olacak gelişmeleri içinde barındırmaktadır. Daha verimli ve üretken sistemlere ulaşmayı hedefleyen Endüstri 4.0 çalışmaları, bu amaç ile çeşitli teknolojilerin bir arada kullanılmasına öncülük etmektedir (Lu, 2017:1; Rüssmann vd., 2015:1). Teknoloji yoğun iş modelleri ile farkını ortaya koyan bu yenidünya trendi, Dünya'nın önde gelen sanayi uluslarının birçoğunu gelişmiş üretim yöntemlerini kullanarak yenilikçilik ve tasarım geliştirmeye yönelik girişimlere yatırım yapmaya zorlamaktadır. Bu yatırımın büyük bir kısmı, Endüstri 4.0 gibi akıllı fabrikaların ve akı1lı üretimin norm olduğu bir geleceği başarmaya çalışan vizyonlar tarafından yönlendirilmektedir (Thames ve Schaefer, 2016:12).

Endüstri 4.0'ın literatürde kabul görmüş pek çok tanımı bulunmaktadır. "Karmaşık fiziksel makine ve cihazların, daha iyi iş ve toplumsal sonuçlar için öngörü, kontrol ve plan yapmak için kullanılan ağa bağgl algılayıcılar ve yazılımlarla bütünleştirilmesi”, "ürünlerin yaşam döngüsü boyunca yeni bir değer zinciri organizasyonu ve yönetimi”, "değer zinciri organizasyonu için teknolojiler ve kavramlar için ortak bir terim" tanımları ise bu çalışma kapsamında bahsedilecek durumlara en açıklayıcı başlıkları içermektedir (Hermann vd., 2016:3933; Shafiq vd., 2015:1147-1148). Endüstri 4.0, internetin sağlamıș olduğu bağlantı gücünün etkisi ile iș süreçlerine "akıl” katan bir endüstrinin var oluşunu temsil etmektedir. Endüstri 4.0'ın amacı, insandan arındırılmış bir işletme sistemi yaratmak değildir. Tam tersine, işletmelerde insan faktörünü daha çok kontrol ve yönetim alanına odaklı tutarak, işletmelerin kas ve işletim gücünün robotlara bırakılmasının sağlanmak istenmesidir. Yine karar verme mekanizmalarında yapay zekâ sistemlerinin kullanılması da otomasyon alt yapılı sistemlerin deneyimsel hareketler ile öğrenen yapılara dönüşmelerini sağlamaktadır (Wan vd., 2015:135-136). Endüstri 4.0, bir devrim şeklinde yarattığ 1 tüm bu endüstriyel gelişmeler ile itici bir güç olarak, geleneksel sanayi üretim yöntemlerini değiştirmekte ve gelecekteki üretime rehberlik etmektedir (Zhou vd., 2015:2147).

İş Süreçleri Yönetimi (Business Process Management / BPM) de, yeni iş modellerinin kurulmasında sunduğu bütüncül bakış açısıyla, Endüstri 4.0 başlığı ile birlikte çalışılması gereken konulardan birisidir. BPM işletmelerin, pazarın ve müşterilerinin sürekli değişen gereksinimlerine daha hızlı organizasyonel adaptasyon sağlayabilmeleri için kullanılmaktadır. Ayrıca BPM, kurumsal stratejilerin geliştirilmesi ile sürekli iyileştirmeyi olanaklı kılarak, işletmelerin değer yaratan tamamlayıcı iş süreçlerine odaklanmalarını sağlamaktadır (Neubauer, 2009:167). BPM'in, işletmelerin bir düzen ve sistematik içerisinde çalışmalarını sağlamakla beraber onları ileriye götüren ve aynı zamanda değerini arttırdığı bu yapı, Endüstri 4.0 ile ortak paydasıdır.

Akıllı iş süreçlerinin yönetimi, Endüstri 4.0'ın üç ana hattı bir araya getirmesi ile gerçekleşmektedir. A $\breve{g}$ nesneleri-insanlar ve sistemler; Nesnelerin İnterneti, Hizmetlerin İnterneti ve İnsanların İnterneti olarak birbirine entegre bir hale gelmektedir. Bu bütünleşmedeki en uygun kombinasyon, akıllı fabrika, iş ve sosyal platformlar aracıllı̆̆ıla en iyi prensipleri birleştirmekte ve akıllı iş süreçleri yönetimi oluşmaktadır. Akıllı iş süreçleri yönetimi, etkin ve gerçek zamanlı veri alışverişi sayesinde, güvenlik ve güvenilirliği ön planda tutan iş süreçlerinin başlatma, planlama, çizelgeleme ve gerçekleştirmenin doğru işlevselliğini garanti etmektedir (Chromjakova, 2017:11).

Literatürde akıllı iş süreçleri yönetimi ve Endüstri 4.0'1 bir arada konu alan çalışmalar, kalite, maliyet ve performans etkenleri üzerinde durmaktadır. Hitpass (2019:3) çalışmasında Endüstri 4.0'ın iş süreçleri ve eticaret kavramlarına yeni bir eğilim yönünde etki edeceğinden bahsetmektedir. Endüstri 4.0 ile merkezi olmayan ve daha fazla karar alma özerkliğine sahip süreçler yaratılmakta, e-ticaret entegrasyonunun iş süreçlerine etkisi ise işlemlerin daha etkin ve kontrollü yapılmasını sağlaması olarak açıklanmaktadır. Kullanılan akıllı iş süreçlerinin yönetiminin, çevreyle uyumlu lojistik organizasyon sağlaması, kalite ve performans iyileşmesi ve gelişimini mümkün kılması beklenmektedir. Schoenthaler vd. (2015:7) Endüstri 4.0 teknolojileri ile iş süreçlerinin temelini oluşturan farklı bileşenler arasında yer alan iletişim ve performans ilişkileri tanımlanmaktadır. IoT fonksiyonları ile bir internet servisi aracılığıyla düşük maliyetli bir şekilde dağıtılan bulut bilişim hizmetleri Endüstri 4.0'1n çözümlerini karakterize ettiği ve sürdürülebilir rekabet avantajları sağlayarak, iş süreçleri yönetimine dijital destek olduğu açıklanmaktadır.

$\mathrm{Bu}$ çalışmada, Endüstri 4.0 uygulamalarının iş süreçleri yönetimine etkisi üzerine inceleme yapılması amaçlanmaktadır. Bu kapsamda öncelikle Endüstri 4.0 ve içerdiği başlıklar, İş Süreçleri Yönetimi konusu, ortaya çıkışı ve zaman içinde teknoloji ile yeni trendler karşısında yaşanılan değişimler ve akı1lı iş süreçleri 
yönetimi açıklanmıştır. Ardından çalışmanın uygulama bölümünde, geleneksel depolama sistemini akıllı depolama sistemine dönüştüren bir işletmenin Endüstri 4.0 teknolojileri ile iş süreçleri yönetiminde yaşadığg değişimin verimlilik, işgücü, maliyet parametreler kullanılarak karşılaştırılması yapılmıştır.

\section{IŞ SÜREÇLERİ YÖNETIMİ (BUSINESS PROCESS MANAGEMENT / BPM)}

İş Süreçleri Yönetimi (BPM), iş süreci yeniden yapılanması, iş süreci inovasyonu, iş süreçleri modellemesi ve iş süreçleri otomasyonu gibi bir dizi yaklaşımda önerilen hedefleri, sistemleri, yöntem ve araçları bir arada ele alan bütüncül bir kavramdır. İşs süreçlerinin analizi bir örgütün köklerine inilmesine olanak sağladığından, BPM çağdaş yönetim yaklaşımlarından biri olarak kabul edilmektedir (Rosemann ve Bruin, 2005:3). BPM, başlangıçta bilişim sistemleri başlı̆̆ 1 altında çalışılmış, 1980'lerin sonlarından bu yana ise uygulamada yoğun olarak tartışılan bir konu olmuştur. Daha önceki çalışmalar ile süreç oryantasyonu fikri tartışılmış olsa da (Nordsieck, 1934), 1990'ların başından itibaren, Davenport ve Short (1990), Hammer ve Champy (1993) ve Scheer (1994)'ın katkıları ve sunulan kavramların pratik uygulaması konu üzerinde önemli bir etkiye sahip olmuştur. Yapılan yönetim araştırmaları, BPM'nin geçici bir yönetim modası olmadığını ortaya çıkarmış ve araştırmacılar BPM'nin belirli bir olgunluğa erişmesini sağlayan çok sayıda teorik ve ampirik çalışma yaparak konuya katkı sağlamışlardır (Houy vd., 2010:619).

$\mathrm{BPM}$, iş süreçlerini stratejik hedefler ve müşterilerin ihtiyaçları ile uyumlu hale getirmeyi amaçlamaktadır. Bu bağlamda, Elzinga vd. (1995:119) BPM'i "ürün ve hizmet kalitesini iyileştirmek amacıyla süreçleri analiz etmek, geliştirmek, kontrol etmek ve yönetmek için sistematik ve yapılandırılmış bir yaklaşım" olarak tanımlamaktadır. Zairi (1997:64) ise BPM'i "bir işletmenin faaliyetlerinin imalat, pazarlama, iletişim ve diğer kilit unsurları gibi önemli etkinlikleri analiz etmek ve sürekli olarak geliştirmek için yapılandırılmış bir yaklaşım" olarak açıklamaktadır. Bu tanımlar ile BPM bir iş yönetim modeli olarak ele alınmakta ve işletme hedeflerine göre yapılandırılması gerektiği ortaya çıkmaktadır. Ayrıca hedefleri arasında rekabet üstünlüğ̈̈ü sürdürmek olan ve dolayısıyla hızla artan küresel rekabet karşısında, sürekli olarak en iyi uygulama yönetimi ilkelerini, stratejilerini ve teknolojilerini uygulamak zorunda olan işletmeler için BPM başarılı bir uygulama yönetimi ilkesidir (Kilmann, 1995:178).

\section{ENDÜSTRİ 4.0}

Endüstri 4.0, birçok modern otomasyon sistemini, veri alışverişini ve üretim teknolojilerini içeren kolektif bir terimdir ve dünyanın içinde bulunduğu hızla gelişen dijital dönüşümü temsil etmektedir. Teknolojide yaşanan bu dijital dönüşüm mevcut iş modellerini de etkilediğinden, bu değişikliğe Dördüncü Sanayi Devrimi adı verilmiştir (Bilgin Sarı, 2018:2). Buhar gücüyle başlayan ve ilerleyen dönemlerde elektrik gücüyle evrilen mekanik sistem kurulumları, makineleşme ve bilgi çağının kazandırdığı bilgi teknolojilerinin birbirleriyle olan entegrasyonu sonucu Endüstri 4.0'1 oluşturmuş ve 21. yüzyıl endüstri işletmelerinin odak noktası haline gelmiştir.

Endüstri 4.0'ın ana eğilimleri Mosterman ve Zander (2016) tarafından; Nesnelerin İnterneti (Internet of Things / IoT), Makine Teknolojileri ve Siber-Fiziksel Sistemler (Cyber-Physical System / CPS) olarak tanımlanmaktadır. Özellikle, üretim ortamında CPS'nin araştırma modelleri ve uygulamaları, literatürde sıkça tartışılmaktadır (Lee, 2008; Lee vd., 2015). CPS, insanlar, makineler ve ürünler arasındaki iletişimi mümkün kılmaktadır. Bu sistemler verileri edinebildikleri ve işleyebildikleri için, belirli görevleri kendileri kontrol edebilir ve arayüzler aracılığıyla insanlarla etkileşime girebilirler. Ayrıca, akı1lı üretim ortamında, akıllı ve özelleştirilmiş ürünler, üretim süreci ve tüketici uygulaması bilgisini içermekte ve tedarik zincirinde bağımsız olarak yol alabilmektedir (Brettel vd., 2014:38). Şekil 1 ile CPS'nin iş süreçleri iletişiminde aldığı rol gösterilmektedir (Geisberger ve Broy, 2012:56). 
Şekil 1. Siber - Fiziksel Üretim Ağı Diyagramı
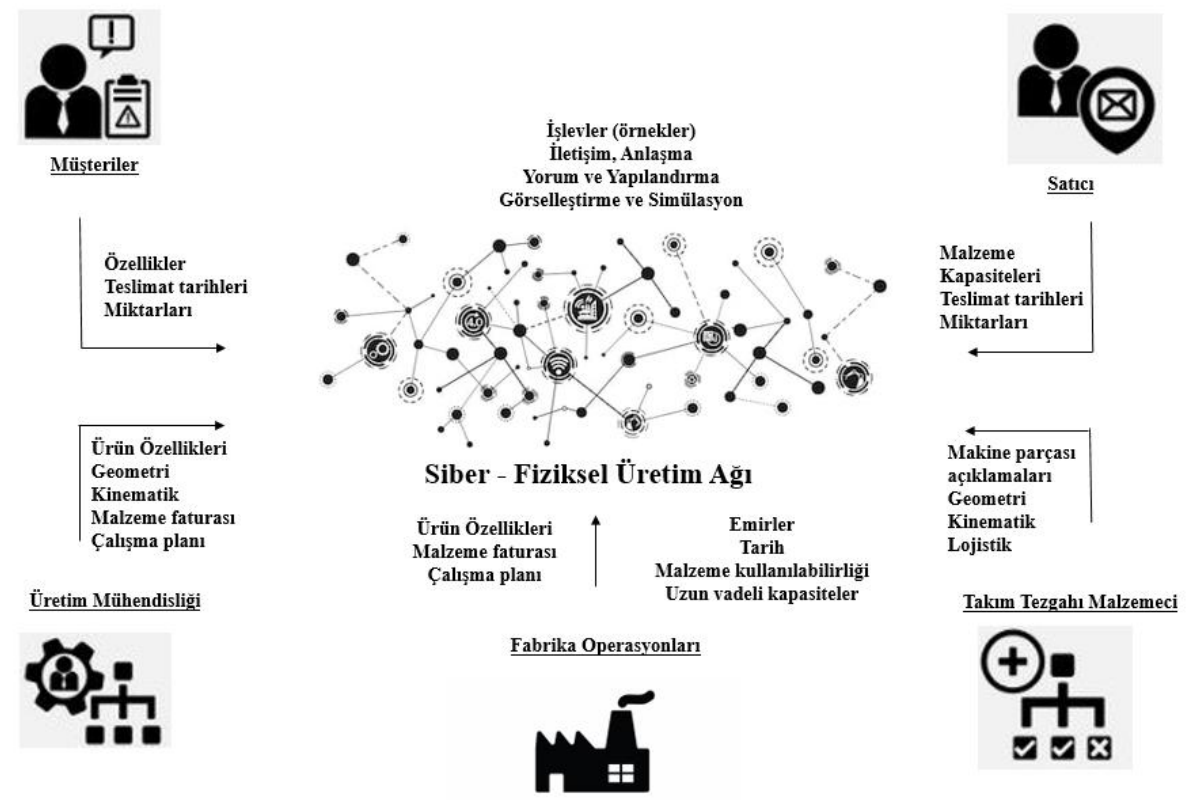

Kaynak: Geisberger ve Broy, 2012:56.

IoT ise Endüstri 4.0'daki bir diğer önemli başlıktır. İnsan kontrolündeki fiziksel nesnelerin birbirine bağlanması daha açık bir ifadeyle, sensörler, aktüatörler (bir sistemi kontrol eden veya hareket ettirmesine yarayan bir tür motor) ve internete bağlanma araçları ile donatılması anlamına gelmektedir (Dijkman vd., 2015:672). IoT, Endüstri 4.0'dan daha eski bir kavram olmasına rağmen yeni sanayi devrimiyle daha fazla gündeme gelerek uygulama alanları her geçen gün artmaktadır. Yeni pazar gereksinimleri de işletmeleri IoT gibi otonom teknolojileri kullanarak akıllı sistemler kurmaya doğru yöneltmektedir. IoT ile fiziksel nesneler iş süreçlerine aktif olarak katılmakta ve bilgi ağına sorunsuz bir şekilde entegre olmaktadırlar. Otomasyon teknolojileri, hem geleneksel hem de yenilikçi işletmeler tarafından, idari ve üretim süreçlerinin kalitesini ve verimliliğini arttırmak, e-ticaret işlemlerini yönetmek ve hızlı ve güvenilir bir şekilde teslim etmek üzere hizmetleri kullanmak için giderek daha fazla kullanılmaktadır (Grigori vd., 2004:321).

\section{ENDÜSTRİ 4.0 VE AKILLI İŞ SÜREÇLERİ YÖNETIMİ}

Akıllı iş süreçleri üzerine literatürde yapılan çalışmalar bu konunun bütünsel yönünü açıklamak için incelendiğinde, IoT teknolojisinin süreç yönetiminin etkinliğini pozitif yönde etkilediği görülmektedir. Heil vd. (2007), IoT'nin bağlama niteliğine vurgu yapmaktadır. IoT bağlamı, sensörler tarafından ilgili nesneler, ilgisiz nesneler ve ilgili nesneler arasındaki ilişkiyi okumasına göre değişmektedir. Ayrıca IoT geleceğin interneti olarak da değerlendirilmekte ve kendi kendini yapılandırabilen, kimliği ve aklı olan fiziksel ve sanal şeylerin bir bütün olduğu bir ağ olarak tanımlanmaktadır (Vermesan vd., 2009:10). Michael vd. (2010), IoT için fiziksel cisimlerin içine yerleştirilmiş sensör ve aktüatörlerin kablolu veya kablosuz olarak internete bağlanması ifadesini kullanmaktadır. Atzori vd. (2010), nesneler ve internete üçüncü bir boyut daha ekleyerek, IoT’yi, nesneler, internet ve semantik boyutlarının kesişim alanı olarak tanımlamaktadır. Ning ve Hu (2012) IoT ile akıllanma ve bilgi gelişimi döneminin başladığını ve IoT’nin kullanım alanının yaygınlığından bahsetmektedir. Leary (2013) çalışmasında ise, IoT, büyük veri ve sembollerin interneti kavramlarının gelişimi ile bu kavramlar arasındaki ilişkiyi araştırmakta, sensörlere dayalı bilgi ile insan kaynaklı bilginin entegre edilmesinin daha değerli bir bilgi sağladığı yönünde sonuçlara ulaşmaktadır.

IoT fiziki bir varlığı olan nesnelerin başka nesnelerle ve başka veri ağlarıyla bağlantılı olduğu bir iletişim şebekesidir. IoT yardımı ile büyük işletmeler müşterilerinin tüketim alışkanlıklarını faydalanarak izleme imkânına dahi sahip olmaktadır. Bu sayede internet, büyük veri ve teknolojiden takip edilerek öngörülen satış stratejilerine göre satın alma olasılığı göreceli olarak daha yüksek olan ürünlerin pazarlamasını yönetmekte ve iş süreçlerine yansımalarını takip edebilmektedir.

Armistead ve Machin, (1997), işletmelerin süreçlerini yönetme konusunda BPM'i kılavuz almaları konusunda itici faktörleri; küreselleşme, değişen teknoloji, yasal düzenlemeler, paydaşların tutumu ve iş sınırlarında yaşanan değişimler olarak açıklamaktadır (Lee ve Dale, 1998:214-215). Günümüz koşulları altında, hem rekabet 
üstünlüğü elde edebilmek hem de yaşanan değişimlere uyum sağlayabilmek için dijital teknolojilerden yararlanmaktadır. Yeni çağda, dijital teknolojiler hâlihazırda mevcut iş uygulamalarını değiştirmekte ve işletmelerini iş süreçlerini yeniden ele almaya zorlamaktadır (Matt vd., 2015:339). Jesus ve Rosemann (2017), BPM'in geleceği ile ilgili çalışmalarında endüstri çağı ve dijital çağı karşılaştırmışlardır. Tablo 1'de bu yeni başlık açıklanmaktadır.

Tablo 1. Endüstri Çağı ve Dijital Çağ’da BPM

\begin{tabular}{|c|c|}
\hline \multicolumn{2}{|c|}{ İş Süreçleri Yönetimi } \\
\hline Endüstri Çağı & Dijital Çağ \\
\hline İş süreçleri & Müşteri süreçleri \\
\hline Seri üretilen süreç & Kitlesel birleştirilmiş süreç \\
\hline Tek kaynaklı ( insan veya makine ) & Melez kaynak \\
\hline Sorun odaklı iş süreçleri & Firsat odaklı iş süreçleri \\
\hline İşlem süresi & İşlem gecikmesi \\
\hline Kurumsal fikirli iş süreçleri yönetimi & Girişimci fikirli iş süreç tasarımı \\
\hline Kar kaynaklı iş süreçleri & Amaç odaklı iş süreçleri \\
\hline
\end{tabular}

Kaynak: Jesus ve Rosemann, 2017:4.

Jesus ve Rosemann (2017), çalışmalarında, BPM'in endüstri çağından dijital çağa geçişte önemli değişiklikler ile karşı karşıya olduğunu vurgulamaktadır. Birinci maddede; iş süreçleri anlayışı, endüstri çağ temelli işletmelerin ekonomik yapısının dijital olarak güçlendirilmiş bir müşteri odaklı ekonomiye geçerken bir dönüşüm yaşadığı açıklanmaktadır. $\mathrm{Bu}$ durum iş süreçlerinden müşteri süreçlerine doğru geçiş olarak tanımlanabilir. Müşteri süreçleri örgütsel sınırlara bağlı olmayacağından geleneksel bakış açısını genişletecektir. İkinci madde ise çoğu geleneksel süreç tanımı ile yığın üretim gibi önceden tanımlanmış faaliyetlerin net bir şekilde yürütülmesi açıklanmaktadır. Bu noktada kurallar ve prosedürler en nihayetinde öngörülebilirliğe dayalıdır. Dijital çağda ise, bu yapının kişiselleştirilmiş kitlesel süreçlere dönüşeceği düşünülmektedir. Üçüncü olarak ele alınan konu ise bazı iş süreçlerinin, dijital okuryazarlığı yüksek seviyede olan yetkilendirilmiş insanlar tarafından yönetileceğine yöneliktir. Birçok iş sürecinin ise otomasyona dayalı olarak robotik algoritmalar tarafından, insan müdahalesinden bağımsız şekilde yürütüleceği yönündedir. Bu durum, insanlar, makineler ve nesneler bir arada olarak bir tür hibrit kaynak oluşumuna neden olacaktır. Dördüncü madde ise, dijital teknolojilerin sunduğu faydalardan yararlanmak amacıyla, BPM'in problem çözücü yaklaşımdan ziyade fırsat odaklı bir bakış ile ele alınması olarak açıklanmaktadır. Beşinci maddede işlem süresi ele alınmaktadır. Burada; işlemler özel bilgilerini ve dijital kimliklerini güvenilen ve korunan kanallar aracıllı̆ıyla paylaşan müşterilerin iş süreçlerinin hızlı bir şekilde görülmesinin rekabet avantajına dönüştürülebileceği üzerinde durulmaktadır. Altıncı olarak, iş süreçleri yapısının kurumsallıktan ziyade, girişimciliğe yönelik olacağ 1 yönünde bir anlayıştan bahsedilmektedir. Son olarak ise, daha geniş anlamda, yeni iş gücünün farklı iş deneyimleri aradığı yeni bir dünya ile karşı karşıya olunan durumda, kar odaklı işletme anlayışı yerine amaç odaklı iş anlayışı savunulmaktadır.

Diğer taraftan pek çok işletme ortaya çıkan dijital teknolojiler hakkında bilgi sahibi olmadıkları gibi, iş süreçlerini geliştirmek için hangi teknolojilerin benimsenmesi gerektiğini belirlemekte de eksik kalmaktadır (Hbras, 2015:46). Bu nedenle uygulama çalışmaları yapılmasına olanak sağlanması ve iş süreçlerini geliştirmek için kullanılan yöntemlerin açıklandığı araştırmaların yayınlanmasına ihtiyaç duyulmaktadır. Bu bağlamda bu çalışmada yapılan uygulama çalışması ile bu ihtiyaç karşılanmaktadır. Depolama süreçlerinin yeniden ele alındığı ve akıllı depolama sisteminin kurulduğu bir vaka çalışması detaylandırılmaktadır. 


\section{DEPOLAMA SÜREÇLERINIIN DİJITAL DÖNÜŞÜMÜ UYGULAMASI}

Ürünlerin depo raflarına yerleştirilmesi ve alınmasında, insan gücünden ya da insan operatör kontrolünden faydalanılmaktadır. Ancak insan faktörü, ürün zedelenmesi, yanlış ürün sevkiyatı, ürünlerin depoda raf ömürlerini tamamlaması, zaman kaybı gibi birçok hataya sebep olmaktadır. Bu durumda depolama süreçlerinin yeniden ele alınarak Endüstri 4.0 uygulamaları ile desteklenen Akıllı Depolama Sistemi (ADS) kurulması gerekmektedir. Uygulamada ele alınan ADS ile depo alanının daha verimli kullanılması, depolama ve boşaltma zamanının kısaltılması, hatasız ürün sevkiyatı, ürünlerin zarar görmemesi, stok durumunun ve depo hareketlerinin uzaktan izlenebilmesi, düşük işletme maliyeti, muhasebe sistemine entegre edilebilmesi, iş güvenliği ve depreme karşı mukavemet gibi avantajlar elde edilmektedir.

ADS yardımı ile raf konstrüksiyonun paletlenmiş ürünleri ilgili raf adreslerine taşıması ve bu adreslerden geri alacak olan robotun kontrolü sağlanmış olmaktadır. ADS uygulamasının amacı;

- Üretim, depolama ve lojistik arasındaki bağı en etkin şekilde kullanmak

- Düşük işçilik maliyetiyle depolama boşaltma sürecini yönetmek

- Müşterilerden gelen ürün taleplerine hızlı yanıt vermek

- Hızlı depolama ve boşaltma olanağı sağlamak

- İnsan faktörünün depolama ve boşaltma sürecine etkisini azaltmak

- Bilgisayar destekli stok kontrolü sağlamak

- Ürünü, pazara miadı dolmadan ve en kısa sürede ulaştırmak

- Uzaktan kontrol edilebilir bir sistem kurmak

- İş kazalarını önlemek

- Enerji verimliliği sağlamak olarak sıralanabilir

ADS oluşturulmadan önce, depolama işlemleri geleneksel depolama sistemi ile yapılmaktaydı. Bu yapıda üretim alanından çıkan tamamlanmış ürün, depolama sahası önünde beklemekte ve istiflenmektedir. Tamamlanan ürünlerin bilgi kartları belirli aralıklarla personel yardımı ile toplanmakta ve depo yöneticisine iletilmektedir. Ürünler depo yönetimi tarafından tayin edilen yere forkliftler aracılığıyla taşınmakta ve raflanmaktadır. Geleneksel Depolama Sürecinin Aşamaları Şekil 2'de gösterilmektedir.

Şekil 2. Geleneksel Depolama Süreci

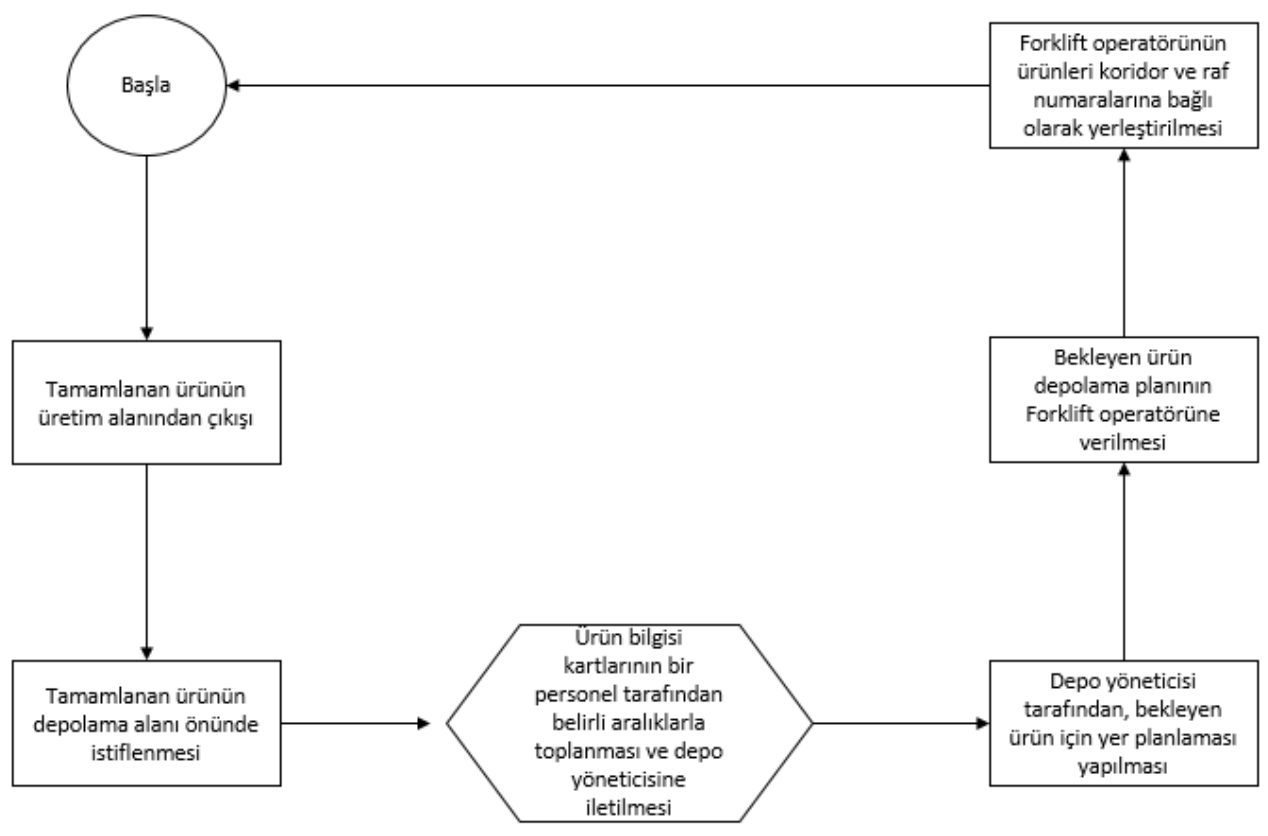

Kaynak: Yazarlar tarafından hazırlanmıştır 
Yaşanan teknolojik gelişmeler ışı̆̆ında oluşturulan akıllı depolama sistemi, robotik tabanlı olup, insansız ve yapay zeka ile yönetilmekte ve işlenmektedir. Bu sistemde, depolama işleminin başladığı nokta, paletleme robotu ve ADS'nin birleşim noktası olan konveyor hattıdır. Bu konveyör hattının sonunda, ambalajlı ürünlerin ahşap paletler üzerinde istiflenerek bir araya getirilmekte ve paletler ray üzerinde siralanmaktadır. Sıralanan paletlerin barkodunda tanımlanan ürün bilgileri veri tabanına paletleme sürecinde aktarılmaktadır. Paletler taşıyıcı robot ile ray üzerinden alınarak koridor robotu üzerine taşınmaktadır. Koridor robotu algoritma tarafindan belirlenen hücre adresinin bulunduğu noktaya gelerek taşıyıcı robotun raya geçmesini beklemektedir. Taşıyıcı robot, raya geçtikten sonra paleti adresine bırakıp boş halde tekrar koridor robotuna dönmektedir. Böylelikle depolama işlemi tamamlanmış olmaktadır. Bu sürecin aşamalarını Şekil 3'te gösterilmektedir.

Şekil 3. Akıllı Depolama Süreci

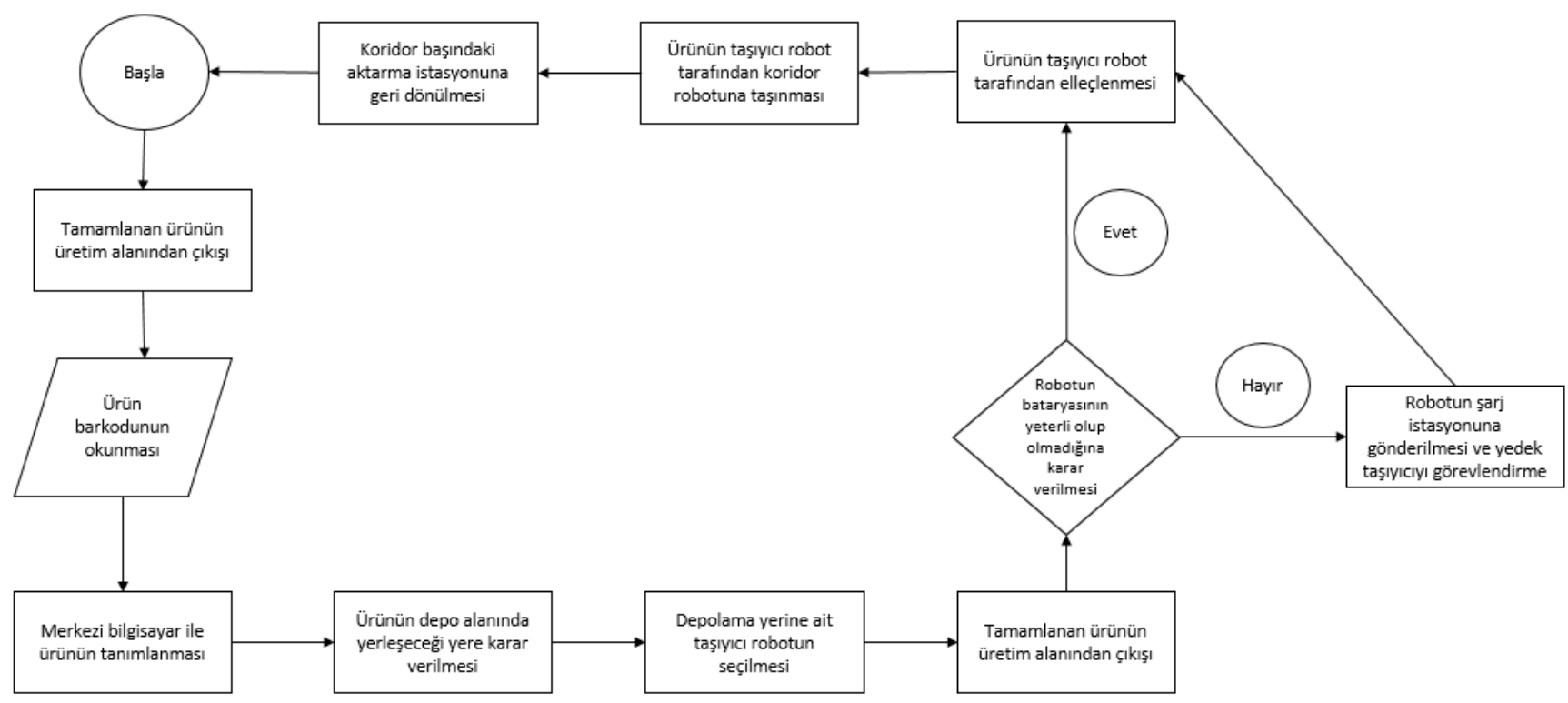

Kaynak: Yazarlar tarafindan hazırlanmıştır

ADS, depolama süreci ile ilgili olduğu kadar boşaltma süreci ile de ilgilidir. Geleneksel yapıda boşaltma süreci, geleneksel depolama sürecine benzer olarak depo yöneticisi ve forklift çalışanları yardımı ile işlemektedir. Satış birimi tarafından satılan ürün bilgisinin depo yöneticine gönderilmesinin ardından, depo yöneticisi sevkiyat talimatı hazırlamakta ve forklift operatörü satılan ürünü rafta bularak sevkiyat alanına taşımaktadır. Şekil 4'te Geleneksel Boşaltma Sürecinin Aşamaları gösterilmektedir.

Şekil 4. Geleneksel Boşaltma Süreci

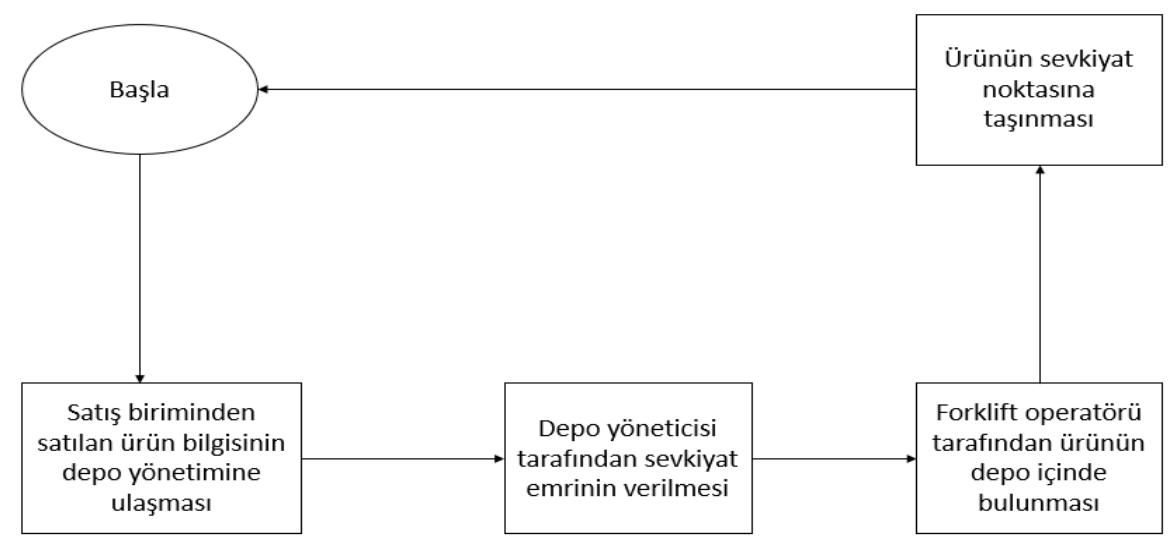

Kaynak: Yazarlar tarafindan hazırlanmıştır

ADS ile yönetilen boşaltma işleminde algoritmanın seçtiği taşıyıı robot, bulunduğu konumdan ilgili koridor robotuna yönelerek ve boş halde koridor robotunun üzerine binmektedir. Koridor robotu alınacak paletin adres girişine giderek taşıyıcı robotun raya geçmesini beklemektedir. Raya geçen taşıyıcı robot, paleti hücreden alarak ve koridor robotuna yüklü bir şekilde geri binmektedir. Koridor robotu, yüklü taşıyıcı robotu raf sisteminin ön rayına getirerek bu raya geçmesini beklemektedir. Raya geçen ürün yüklü taşıyıcı robot sevkiyat yükleme 
noktasına giderek paleti bırakmaktadır. Böylece boşaltma işlemi tamamlanmış olmaktadır. Bu sürecin adımları Şekil 5'te gösterilmektedir.

Şekil 5. Akı1lı Boşaltma Süreci

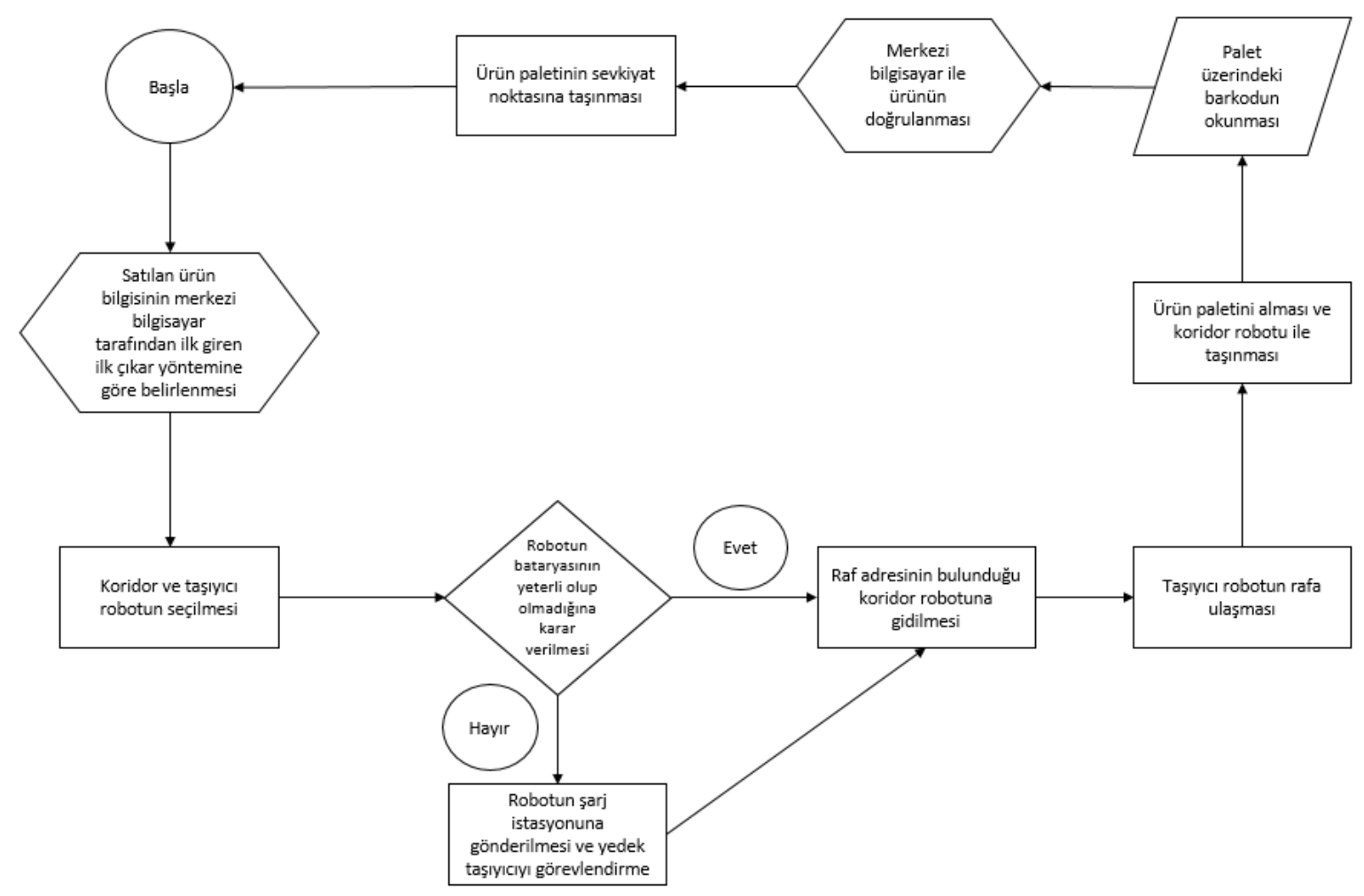

Kaynak: Yazarlar tarafından hazırlanmıştır

\section{UYGULAMA SONUÇLARI}

Klasik depolama sistemine sahip olan işletmede, üretiminden çıkan bitmiş ürün paletleri yaklaşık $14.000 \mathrm{~m}^{2}{ }^{2}$ lik alanda depolanmaktadır. Paletler üst üste depolanamadığ 1 için de kapladığ kullanılmaktadır. ADS kurulumu ile birlikte 4 katlı otomatik depolama sistemine sahip olan işletme, sadece hacim kullanımından değil aynı zamanda operasyonel işleyişinde aşağıda detayları anlatılan işçilik, forklift, enerji, yatırım maliyeti gibi birçok alanda tasarruf sağlamaktadır.

- İşçilik Tasarrufu: Geleneksel sistemde işletmede üretimden bitmiş ürün paletlerinin depolama alanına taşınmasında her bir vardiyada 3'er adet olmak üzere 2 vardiyada toplam 6 adet forklift operatörü iş görmektedir. Paletlerin sevkiyat için taşınmasında ise günde 2 forklift operatörü çalışmaktadır. Yukarıda; tanımlanan operasyonlar için işletme bünyesinde toplamda 8 adet forklift operatörü istihdam etmektedir.

ADS'nin kurulması ile üretimden depolama alanına bitmiş ürün paletlerinin taşınmasında her vardiyada 1 forklift operatörü, depo alanından sevkiyat yüklemesine ise vardiyada 1 forklift operatörü ile toplamda 4 adet işçi ile sistem işleyişi gerçekleştirilmektedir. Y1llık işçilik maliyeti Tablo 2'de verilmiştir.

Tablo 2. Yıllık İşçilik Maliyeti Karşılaştırması

\begin{tabular}{|c|c|c|c|c|c|}
\hline DEPOLAMA SISTEMI & $\begin{array}{c}\text { Üretim-Depo } \\
\text { Alanı Forklift } \\
\text { Operatörü SayıSı }\end{array}$ & $\begin{array}{c}\text { Depolama-Sevkiyat } \\
\text { Alanı Forklift } \\
\text { Operatörü Sayısı }\end{array}$ & $\begin{array}{c}\text { 1 Forklift } \\
\text { Operatörü } \\
\text { Maliyeti/Yıl }\end{array}$ & $\begin{array}{c}\text { Toplam } \\
\text { İş̧̧i Sayısı }\end{array}$ & $\begin{array}{c}\text { Isş̧̧ilik } \\
\text { Maliyet/Yıl }\end{array}$ \\
\hline Geleneksel Depolama Sistemi & 4 & 4 & 65.000 & 8 & 520.000 \\
\hline Akılı Depolama Sistemi & 2 & 2 & 65.000 & 4 & 260.000 \\
\hline
\end{tabular}

Kaynak: Yazarlar tarafından hazırlanmıştır 
Sonuçta; ADS ile birlikte 4 adet forklift operatörü maliyeti ortadan kalkmaktadır.

- Forklift Tasarrufu: Geleneksel depolama sistemi, 8 işçi 4 adet forklift kullanımı ile çalıştırılmaktadır. ADS ile birlikte bu sayı 2 forklifte düşmektedir. Yıllık forklift bakım maliyeti ortalama 10.000TL olmaktadır. Y1llık forklift maliyeti Tablo 3'te verilmiştir.

Tablo 3. Yıllık Forklift Maliyeti Karşılaştırması

\begin{tabular}{|c|c|c|c|}
\hline DEPOLAMA SİSTEMI & $\begin{array}{c}\text { Kullanılan } \\
\text { Forklift Sayısı }\end{array}$ & $\begin{array}{c}\text { 1 Forklift Bakım } \\
\text { Maliyeti/Yıl (ort.) }\end{array}$ & $\begin{array}{c}\text { 1 Forklift Operatörü } \\
\text { Maliyeti/Yıl }\end{array}$ \\
\hline Geleneksel Depolama Sistemi & 8 & 10.000 & 80.000 \\
\hline Akılı Depolama Sistemi & 2 & 10.000 & 20.000 \\
\hline
\end{tabular}

Kaynak: Yazarlar tarafından hazırlanmıştır

ADS ile hem forklift makine kullanımı hem de forkliftin bakım giderlerinden tasarruf sağlanmaktadır.

- Enerji Verimliliği: Forkliftten tasarruf yapıldığında toplamda günlük 3 kez şarj etme için gerekli olan enerji maliyeti azaltılmış olmaktadır. Forkliftlerin şarjı için yıllık enerji maliyeti Tablo 4 'te verilmiştir.

Tablo 4. Forklift Yıllık Şarj için Elektrik Enerjisi Maliyeti

\begin{tabular}{|c|c|c|c|c|}
\hline DEPOLAMA SISTEMI & $\begin{array}{c}1 \text { Şarj için sarf edilen } \\
\text { elektrik Kwh }\end{array}$ & Kwh Fiyatı & $\begin{array}{c}\text { Şarj } \\
\text { Sayısı/Gün }\end{array}$ & $\begin{array}{c}\text { Şarj } \\
\text { Maliyet/Yıl }\end{array}$ \\
\hline Geleneksel Depolama Sistemi & 25 & $\mathbf{0 , 7 1 0 ~ T L}$ & 24 & 127.800 \\
\hline Akıllı Depolama Sistemi & 25 & $\mathbf{0 , 7 1 0}$ TL & 6 & 31.950 \\
\hline
\end{tabular}

Kaynak: Yazarlar tarafından hazırlanmıştır

- Depolama Alanı: Klasik depolama sisteminde toplamda 1.056 adet paleti depolayabilen işletme, ADS ile depo alanını yaklaşık 4 katına çıkararak 4.392 adet paleti otomatik olarak depolama ve boşaltma imkânına kavuşmaktadır. Ayrıca işletme ADS'den faydalanmayıp aynı işlemi klasik depolama ile yürütmeye devam etse bunun için $3.840 \mathrm{~m}^{2}$ 'lik ek bir alana daha ihtiyaç duyulmaktadır. Bu alanın yapımı için yasal şartlara göre \%60'lık imar iznini göz önünde bulundurulmaktadır. Tablo 5'te depolama alanı maliyetleri verilmektedir.

Tablo 5. Depolama Alanı Maliyetleri

\begin{tabular}{|c|c|c|c|c|c|c|}
\hline $\begin{array}{l}\text { DEPOLAMA } \\
\text { SİTEMİ }\end{array}$ & $\begin{array}{c}\text { Mevcut } \\
\text { Depolama } \\
\text { Alanı }\end{array}$ & Genişleme İhtiyacı & $\begin{array}{l}\text { Birim Arsa } \\
\text { Maliyeti }\end{array}$ & İnşa Maliyet & $\begin{array}{l}\text { ADS Kurulum } \\
\text { Maliyeti (TL) }\end{array}$ & $\begin{array}{c}\text { Toplam } \\
\text { Maliyet } \\
\text { (TL) }\end{array}$ \\
\hline $\begin{array}{c}\text { Geleneksel } \\
\text { Depolama Sistemi }\end{array}$ & 1056 Palet & $\begin{array}{c}3840 \mathrm{~m}^{2} \\
\left(6400 \mathrm{~m}^{2}-\right. \\
\text { \%60imar izni) }\end{array}$ & $600 \mathrm{TL} / \mathrm{m}^{2}$ & $1000 \mathrm{TL} / \mathrm{m}^{2}$ & - & 7.540 .000 \\
\hline $\begin{array}{l}\text { Akıllı Depolama } \\
\text { Sistemi }\end{array}$ & 4392 Palet & - & - & - & 1.275 .000 & 1.275 .000 \\
\hline
\end{tabular}

Kaynak: Yazarlar tarafından hazırlanmıştır 
İşletme ADS kurulması ile geleneksel depolama sisteminde karşılaşacağ 1 pek çok maliyetten kurtulmuştur. İşçilik, Forklift kullanımı, enerji ve yatırım maliyeti başlıkları altında tek tek incelenen bu maliyetlerin toplam karşılaştırılması Tablo 6'sa gösterilmektedir.

Tablo 6. Geleneksel Depolama ve Akıllı Depolama Maliyetleri

\begin{tabular}{|c|c|c|}
\hline Maliyet Faktörü & Geleneksel Depolama & Akıllı Depolama \\
\hline İşçilik Maliyeti & 520.000 & 260.000 \\
\hline Forklift Kullanımı & 80.000 & 20.000 \\
\hline Enerji Maliyeti & 127.800 & 31.950 \\
\hline Depolama Alanı Maliyeti & 7.540 .000 & 1.275 .000 \\
\hline TOPLAM & 8.267 .800 & 1.586 .950 \\
\hline
\end{tabular}

Kaynak: Yazarlar tarafından hazırlanmıştır

Sonuç olarak işletme geleneksel depolama yerine akıllı depoalma uygulaması ile işçilik, forklift, forklift bakımı ve enerji kullanım giderlerinden toplamda 415.850 TL tasarruf sağlamaktadır. Ayrıca, yeni bina arsa alım ve inşası ile katlanacağı 7.540.000 TL yatırım maliyetinden ADS sisteminin kurulumu (4 katlı çelik konstrüksiyon raf düzeni, robotik sistem ve raylar, yazılım maliyeti) için harcayacağı 1.275.000 TL ile avantaj sağlamaktadır.

\section{SONUÇ}

Endüstri 4.0, işletme yönetiminde tedarikten üretime pazarlamadan müşteri ilişkileri yönetimine kadar pek çok alanda yarattığı etkiler ile gündemdedir. İş süreçleri yönetimi (BPM) de işletme içinde işlerin bir sistematik dâhilinde yürütülmesinde dikkate alınan önemli bir yol göstericidir. Yaşanan dijital dönüşüm her alanda olduğu gibi BPM üzerinde de güçlü bir etkiye sahiptir. Bu çalışmada Endüstri 4.0 ve BPM bir arada ele alınmıştır ve geleneksel depolama süreçlerinin akıllı süreçlere dönüşmesi incelenmiştir. Akıllı depolama sistemi kuran bir imalat işletmesinde performans göstergeleri olarak, işçilik, enerji, forklift kullanımı ve ihtiyaç duyulan depolama alanı alınmıştır. Kurulan sistem geleneksel sisteme göre pek çok alanda maliyet tasarrufu sağlamış ve gerekecek yeni depolama alanı ihtiyacı da ortadan kaldırmıştır. Bunun yanında kurulan sistem işletmeye zamanında ve hızlı teslim güvenilirlik, kalite, müşteri memnuniyeti konularında da önemli katkılar sağlamaktadır.

$\mathrm{Bu}$ çalışma akıllı sistemlerin avantajlarını göstermek ve uygulama alanlarına dikkat çekmek amacıyla yapılmıştır. İlerleyen çalışmalar için kurulan akıllı sistemlerin tüm işletme operasyonlarına yansıdığı örnek olayların tartışılması hedeflenmektedir. Endüstri 4.0, yaratılan akıllı sistemler ile insansız bir yapı oluşturmay1 değil, kontrol ve yönetim konusunda uzman kişilerin görevlendirildiği mekanizmaları oluşturmayı hedeflemektedir. Bu hedef doğrultusunda yapılan araştırmalar uygulama çalışmalarının fayda eve avantajları konularına dikkat çeker yönde olmakta ve bu uygulamalar günden güne artmaktadır. 
BILGIN SARI, Emre, ÖZVERİ Onur ve ŞENYAY, Umut Ekrem - Endüstri 4.0'ın İş Süreçleri Yönetimine Etkisi: Akıllı Depolama Sistemi Uygulaması

\section{KAYNAKLAR}

ARMISTEAD, Colin, ve MACHIN, Simon (1997), "Implications of Business Process Management for Operations Management”, International Journal of Operations \& Production Management, S.17(9), ss.886-898.

ATZORİ, Luigi, LERA, Antonio ve MORABITO, Giacomo (2010), "The internet of things: A survey". Computer Networks, S.54(15), ss.2787-2805.

BILGIN SARI, Emre (2018), "Reflections of Industry 4.0 To Management of Service Enterprises: Smart Hotels", Uluslararası Güncel Turizm Araştırmaları Dergisi, S.2(2), ss.33-40.

BRETTEL, Malte, FRIEDERICHSEN, Niklas, KELLER, Michael ve ROSENBERG, Marius (2014). "How Virtualization, Decentralization And Network Building Change The Manufacturing Landscape: An Industry 4.0 Perspective", International Journal of Mechanical, Industrial Science And Engineering, S.8(1), ss.37-44.

CHROMJAKOVA, Felicita (2017), "Process Stabilisation-Key Assumption for Implementation of Industry 4.0 Concept in Industrial Company”, Journal of Systems Integration, S.8(1), ss.3-12.

DAVENPORT, Thomas. ve SHORT, James (1990), "The New Industrial Engineering: Information Technology And Business Process Redesign”, Sloan Management Review, S.31(4), ss.11-27.

DİJKMAN, Remco, SPRENKELS, Bruno, PEETERS, Thijs ve JANSSEN, Aiden (2015), "Business Models for The Internet of Things", International Journal of Information Management, S.35(6), ss.672-678.

ELZINGA, D. Jack, HORAK, Tomas, CHUNG-YEE, Lee. ve BRUNER, Charles. (1995), "Business Process Management: Survey And Methodology”, IEEE Transactions on Engineering Management, S.24(2), ss.119-28.

GEISBERGER, Eva ve BROY, Manfred (2012), “Agenda CPS Integrierte Forschungsagenda Cyber Physical Systems", Acatech Studie März 2012, Vieweg, Berlin Heidelberg.

GRIGORI, Daniela, CASATI, Fabio, CASTELlANOS, Malu., DAYAL, Umeshwar, SAYAL, Mehmet, ve SHAN, Ming Chien (2004), "Business Process Intelligence”, Computers in Industry, S.53(3), ss.321343.

HAMMER, Michael ve CHAMPY, James (1993), Reengineering The Corporation: A Manifesto for Business Revolution, Harper Business, New York, NY.

HARVARD BUSINESS REVIEW ANALYTIC SERVICES (2015), Driving Digital Transformation: New Skills For Leaders, New Role For The CIO, Harv Bus School Publ, Cambridge.

HEIL, Andreas, KNOLL, Mirko ve WEİS, Torben (2007), "The Internet of Things-Context-Based Device Federations", In 2007 40th Annual Hawaii International Conference on System Sciences (HICSS'07), IEEE, ss.58-58.

HITPASS, Bernhard ve ASTUDİLLO, Hernan (2019), "Editorial: Industry 4.0 Challenges for Business Process Management And Electronic-Commerce", Journal of Theoretical And Applied Electronic Commerce Research, Universidad de Talca - Chile, S.14(1), ss.I-III.

HOUY, Constantin, FETTKE, Peter ve LOOS, Peter (2010), "Empirical Research in Business Process Management-Analysis of An Emerging Field of Research", Business Process Management Journal, S.16(4), ss.619-661.

JESUS, Leandro ve ROSEMANN, Michael (2017), The Future BPM: Seven Opportunities to Become The Butcher And Not The Turkey, BPT Rends, February.

KILMANN, Ralph (1995), “A Holistic Program And Critical Success Factors of Corporate Transformation”, European Management Journal, S.13(2), ss.175-186.

LEARY, Daniel E. (2013), "Big Data, The Internet of Things And The Internet of Signs”, Intelligent Systems in Accounting, Finance And Management, S.20, ss.53-65.

LEE, Edward A. (2008), Cyber Physical Systems: Design Challenges, IEEE, Berkley - CA.

LEE, Jay, BAGHERI, Behrad ve KAO, Hung An (2015), “A Cyber-Physical Systems Architecture for Industry 4.0-Based Manufacturing Systems", Manufacturing Letters, S.3, ss.18-23. 
LEE, Roy ve DALE, Barrie (1998), "Business Process Management: A Review And Evaluation". Business Process Management Journal, S.4(3), ss.214-225.

LU, Yang (2017), "Industry 4.0: A Survey on Technologies, Applications And Open Research İssues", Journal of Industrial Information Integration, S.6, ss.1-10.

HERMANN, Mario, PENTEK, Tobias ve OTTO, Boris (2016), "Design Principles for Industrie 4.0 Scenarios, in: 2016", 49th Hawaii International Conference on System Sciences (HICSS), IEEE, ss.3928-3937.

MATT, Christian, HESS, Thomas ve BENLIAN, Alexander (2015), "Digital Transformation Strategies". Business \& Information Systems Engineering, S.57(5), ss.339-343.

MICHAEL, Chui, MARKUS, Löffler, ve ROGER, Roberts (2010), "The Internet of Things", McKinsey Quarterly, S.2(2010), ss.1-9.

MOSTERMAN, Pieter.J. ve ZANDER, Justyna (2016), "Industry 4.0 As A Cyber-Physical System Study", Software \& Systems Modeling, S.15(1), ss.17-29.

NEUBAUER, Thomas (2009), "An Empirical Study About The Status of Business Process Management", Business Process Management Journal, S.15(2), ss.166-183.

NING, Huansheng ve HU, Sha (2012), "Technology Classification, Industry, And Education for Future Internet of Things", International Journal of Communication Systems, S.25(9), ss.1230-1241.

NORDSIECK, Fritz (1934), Grundlagen der Organisationslehre (Basics of Organization Theory in German), Poeschel, Stuttgart.

ROSEMANN, Michael ve DE BRUIN, Tonia (2005), "Towards a Business Process Managment Maturity Model", ECIS 2005 Proceedings of The Thirteenth European Conference on Information Systems (Ed. D. Bartmann, F. Rajola, J. Kallinikos, D. Avison, R. Winter, P. Ein-Dor, et al.), 26-28 May - Regensburg (Germany), ss.1-12.

RUSSMANN, Michael, LORENZ, Markus, GERBERT, Philipp, WALDNER, Manuela, JUSTUS, Jan, ENGEL, Pascal ve HARNISCH, Michael (2015), Industry 4.0: The Future of Productivity And Growth in Manufacturing Industries, BCG The Boston Consulting Group, Boston - Massachusetts (US).

SCHEER, August Wilhelm (1994), Business Process Engineering - Reference Models for Industrial Companies, Springer, Berlin.

SCHOENTHALER, Frank, AUGENSTEIN, Dominik ve KARLE, Thomas (2015), "Design And Governance of Collaborative Business Processes in Industry 4.0", In Proceedings of the Workshop on CrossOrganizational And Cross-Company BPM (XOC-BPM) Co-Located With The 17th IEEE Conference on Business Informatics (CBI 2015), Lisbon, Portugal.

SHAFIQ, Syed Imran, SANIN, Cesar, SZCZERBİCKİ, Edward, ve TORO, Carlos (2015), "Virtual Engineering Object/Virtual Engineering Process: A Specialized Form of Cyber Physical System for Industrie 4.0", Procedia Computer Science, S.60, ss.1146-1155.

THAMES, Lane ve SCHAEFER, Dirk (2016), "Software-Defined Cloud Manufacturing for Industry 4.0". Procedia Cirp, S.52, ss.12-17.

VERMESAN, Ovidiu, FRIESS, Peter, GUILLEMIN, Patrick, GUSMEROLI, Sergio, SUNDMAEKER, Harald, BASSI, ALESSANDRO, JUBERT, Ignacio Soler, MAZURA, Margaretha, HARRISON, Mark, EISENHAUER, Markus ve DOODY, Pat (2009), "Internet of Things Strategic Research Roadmap", The Cluster of European Research Projects, Tech. Rep., ss.9-52.

WAN, Jianfu, CAİ, Hu ve ZHOU, Keliang (2015), "Industrie 4.0: Enabling Technologies", In Intelligent Computing And Internet of Things (ICIT), 2014 International Conference on, IEEE, ss.135-140.

ZAİII, Mohamed (1997), "Business Process Management: A Boundaryless Approach to Modern Competitiveness", Business Process Management, S.3(1), ss.64-80.

ZHOU, Keliang, LiU, Taigang ve ZHOU, Lifeng (2015), "Industry 4.0: Towards Future Industrial Opportunities And Challenges", In Fuzzy Systems And Knowledge Discovery (FSKD), 2015 12th Inte. 